\title{
AUDIT OF PSEUDOMONAS AERUGINOSA RESISTANCE TO COMMONLY PRESCRIBED ANTIMICROBIALS
}

Mr S. Mitchell, Dr M. Holmes, Mr G. Rowlands, Dr S. Din, Dr K. Bhatt and Dr K. Banavathi

Department of Otolaryngology, University Hospitals North Midlands

\section{Background}

Otitis externa and chronic suppurative otitis media (CSOM) are common conditions in otolaryngology clinics and are frequently caused by bacterial pathogens. The former is a common condition involving the inflammation or infection of the external auditory meatus that is typically caused by a bacterial pathogen. Pseudomanas aeruginosa is the most commonly identified $\mathrm{p}$ a thoge $\mathrm{n}$, follow ed by Staphylococcus aureus, $\beta$ haemolytic Streptococcus and Candida species ${ }^{1,2}$. Additionally, Pseudomonas aeruginosa is the most common cause of chronic suppurative otitis media.

P.aeruginosa is a Gram negative bacteria that has the ability to either acquire resistant genes from other nearby bacteria or by gene mutations $^{3}$. Ciprofloxacin, which is safe with a tympanic membrane perforation, is often used as a first line treatment topically. However, the incidence of resistance towards ciprofloxacin and other commonly used antibiotics is increasing.

Understanding the resistance pattern of this pathogen is crucial when treating patients that present with either otitis externa or CSOM.

\section{Objectives}

This study set out to identify the local resistance rate of Pseudomonas aeruginosa positive ear swabs to Ciprofloxacin and other common antimicrobials.

\section{Methods}

A retrospective study was carried out over a 24 month period between January 2015 and December 2016. To establish the rate of P.aeruginosa ciprofloxacin resistance, all positive ear swabs for pseudomonas received by the microbiology department were collated and sensitivity profiles recorded. The patient case notes were reviewed for those swabs that were shown to be resistant to ciprofloxacin. The identified ciprofloxacin resistance rate was compared to the reported literature rate.

\section{Results: Overall Pseudomonas resistance}

\begin{tabular}{lccccccc}
\hline \multicolumn{1}{c}{ Antibiotic } & Cipro & Gent & Tazocin & Mero & Imipenam & Ceftazidime & Colistin \\
\hline $\begin{array}{l}\text { Total No. of } \\
\text { samples tested } \\
\text { against Abx }\end{array}$ & 2023 & 2023 & 2022 & 2023 & 1759 & 2023 & 2021 \\
$\begin{array}{l}\text { Sensitive } \\
\text { Percentage (\%) }\end{array}$ & 93.8 & $90 / 8$ & 82.8 & 96.4 & 94.7 & 96.9 & 99.7 \\
\hline Resistant & 126 & 186 & 348 & 72 & 94 & 63 & 7 \\
\hline Percentage (\%) & $\mathbf{6 . 2}$ & $\mathbf{9 . 2}$ & $\mathbf{1 7 . 2}$ & $\mathbf{3 . 6}$ & $\mathbf{5 . 3}$ & $\mathbf{3 . 1}$ & $\mathbf{0 . 3}$ \\
\hline
\end{tabular}

Table 1. Pseudomonas resistance to common antibiotics

\section{Results: Demographics}

A total of 2023 ear swabs cultured Pseudomonas.

\begin{tabular}{lcc}
\hline \multicolumn{1}{c}{ Swab Side } & Frequency & Percentage \\
\hline Right Ear & 696 & $47.9 \%$ \\
Left Ear & 1026 & $50.7 \%$ \\
Undefined & 28 & $1.4 \%$ \\
& 2023 & $100.0 \%$ \\
\hline
\end{tabular}

Average age of patient: 44.45 years Range: 0 - 97 years

\begin{tabular}{lcc}
\hline \multicolumn{1}{c}{ Gender } & Frequency & Percentage \\
\hline Male & 1043 & $51.6 \%$ \\
Female & 949 & $46.9 \%$ \\
Not Stated & 31 & $1.5 \%$ \\
& 2023 & $100.0 \%$ \\
\hline
\end{tabular}

Table 2. Numbers of swabs collected

Table 3. Breakdown of patients by gender

\section{Results: Resistance}

\begin{tabular}{ccc}
\hline $\begin{array}{c}\text { Number of Abx } \\
\text { Pseudomonas } \\
\text { Resistant to }\end{array}$ & Frequency & Percentage \\
\hline 0 & 1436 & $71.0 \%$ \\
\hline 1 & 393 & $19.4 \%$ \\
\hline 2 & 132 & $6.5 \%$ \\
\hline 3 & 35 & $1.7 \%$ \\
\hline 4 & 12 & $0.6 \%$ \\
\hline 5 & 4 & $0.2 \%$ \\
\hline $6 *$ & $11^{*}$ & $0.5 \% *$ \\
\hline 7 & 0 & $0.0 \%$ \\
\hline & 2023 & $100.0 \%$ \\
\hline
\end{tabular}

*9 samples from same patient on different dates, 2 samples no details available and possibly from the same patient.

Table 4. The frequency and percentage of antibiotics that individual samples were resistant to

\section{Discussion}

$P$.aeruginosa, is becoming increasingly resistant to current topical antimicrobial agents. Lister identified the rate of ciproflxacin resistance among $P$.aeurginosa isolates in hospitals and ICU's to range between $21-35 \%{ }^{3}$ Other studies focusing on resistance rates from ear swabs, identify resistance rates to the same antibiotic ranging from $6.2-25 \%{ }^{4-6}$ This study identified a local resistant rate to ciprofloxacin of $6.2 \%$ which is lower compared to other geographical areas. Resistance to gentamicin and Piperacillin/Tazobactam was $9.2 \%$ and $17.2 \%$ respectfully. Additionally $1.7 \%$ of samples were resistant to three or more antibiotics. There is therefore no requirement to cease using ciprofloxacin as a first line antimicrobial to treat suspected or proven pseudomonal ear infections.

\section{Conclusion}

Incidence of Pseudomonas aeruginosa positive ear swabs to ciprofloxacin is relatively low in our area and there is no need to cease using it as a first line agent. The management for those with pathology caused by multi-drug resistant bacteria can be challenging.

References:

${ }^{1}$ Ninkovic G, Dullo V, Saunders NC. Microbiology of otitis externa in the secondary care in United Kingdo Larynx. 2008 Dec, $35(4) .480-4$.

Ricrobiology of acute otitis externa. The

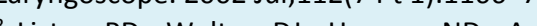

crial Lister PD, Wolter DJ, Hanson ND. Alacteraltion of chromosomally encoded resistance mechanisms. Clin Microbiol Rev. 2009 Oct:22(4):582-610. ${ }^{4}$ Cheong CSJ, Tan LML, Ngo RYS. Clinical audit of the microbiology of otorrhoea referred to a tertiary hospital in Singapore. Singapore Med J. 2012 Apr; $53(4): 244-8$.

${ }^{5}$ Altuntas A, et al. Susceptibility of microorganisms isolated from chronic suppurative otitis media to ciprofloxacin. Eur Arch Oto-Rhino-Laryngol Off Eur Fed Oto-Rhino-Laryngol Soc EUFOS Affil Ger Soc Oto-Rhino-Laryngol
Head Neck Surg. 1996;253(6):364-6.

${ }^{6}$ Le Clerc N, Verillaud B, Duet M, Guichard J-P, Herman P, Kania R. STe 